\title{
DIGESTIBILIDAD APARENTE DE DIETAS CON PROBIÓTICOSO FITASA PARA POTROS MANGALARGA MARCHADOR ${ }^{\#}$
}

\author{
APPARENT DIGESTIBILITY OF DIETS WITH PROBIOTICS OR \\ PHYTASE INMANGALARGAMARCHADORFOALS
}

\author{
Moura, R.S. de ${ }^{1 \mathrm{~A} *}$, Saliba, E.O.S. ${ }^{1 \mathrm{~B}}$, Almeida, F.Q. ${ }^{2}$, Lana, A.M.Q. ${ }^{1 \mathrm{C}}$, Moreira, D.C.A. ${ }^{3}$, \\ Silva, V.P. ${ }^{1 \mathrm{D}}$, Moss, P.C.B. ${ }^{1 \mathrm{E}}$, Pereira, R.V.G. ${ }^{1 \mathrm{~F}}$, Costa, M.L.L. ${ }^{1 \mathrm{G}}$ y Rezende, A.S.C. ${ }^{1 \mathrm{H}}$
}

\begin{abstract}
'Escola de Veterinária. Universidade Federal de Minas Gerais (UFMG). Pampulha. Belo Horizonte-MG. Brasil. A*raquelmourabr@yahoo.com.br; Bsaliba@vet.ufmg.br; Clana@vet.ufmg.br; Dzootenista_ufrrj@yahoo.com.br; Epatriciacbmoss@ig.com.br; Fvitarele@yahoo.com.br; Glindomarciacosta@yahoo.com.br; Hadalgiza@vet.ufmg.br

${ }^{2}$ Departamento de Medicina e Cirurgia. Instituto de Veterinária. Universidade Federal Rural do Rio de Janeiro (UFRRJ). Brasil. falmeida@ufrrj.br

${ }^{3}$ Haras Catuni. Montes Claros. Minas Gerais. Brasil. dalton@catuni.com.br
\end{abstract}

\section{Palavras chave adicionais}

Enzimas. Equinos. Lactobacillus. LIPE ${ }^{\circledR}$. Saccharomyces cerevisiae.

\section{RESUMEN}

El uso de aditivos se ha desarrollado mucho actualmente, con el fin de mejorar el aprovechamiento de la dieta. El presente trabajo se realizó con el objetivo de evaluar los efectos de la suplementación con probióticos o fitasa sobre la digestibilidad aparente (DA) de los nutrientes en 24 potros (16 machos y 8 hembras) Mangalarga Marchador con 241,6 $\pm 23,2$ días de edad y 216,7 $\pm 27,8 \mathrm{~kg}$ de peso vivo (PV). El experimento tuvo duración de 28 días (23 para la adaptación y cinco para la recogida de muestras de heces) y la dieta basal se compuso de pasto de Cynodon y pienso comercial (1,2 kg /100 kg PV), además de agua y sal mineralizada ad libitum. Los tratamientos fueron: dieta basal (T1); dieta basal $+5 \mathrm{~g} /$ día de $10^{9}$ UFC/g de levadura $S$. cerevisiae (T2); dieta basal + $2 \mathrm{~g} /$ día de $10^{8} \mathrm{UFC} / \mathrm{g}$ de bacterias B. bifidum, $E$. faecium, L. acidophilus, L. plantarum y $10^{5}$ UFC/ $\mathrm{g}$ de levadura S. cerevisiae (T3); y dieta basal + 1250 FTU (unidades de fitasa)/dia (T4). La estima-

\footnotetext{
\#Trabajo financiado por la Fundação de Amparo a Pesquisa do Estado de Minas Gerais (FAPEMIG) y premiado por la Real Academia de Ciencias Veterinarias de España con el III Premio "Biovet 2007". (Publicación autorizada).
}

\section{AdDitional KEYWORDS}

Enzymes. Horses. Lactobacillus. LIPE ${ }^{\odot}$. Saccharomyces cerevisiae.

ción del consumo se realizó utilizando el indicador externo LIPE $^{\circledR}$ y la técnica de digestibilidad in situ. El diseño estadístico fue enteramente al azar, en esquema factorial $4 \times 2$, y las medias fueron comparadas por el test $t$ de Student $(p<0,05)$. El grupo T3 tuvo mejor DA de la proteína bruta, cenizas, calcio y fósforo. El grupo T2 tuvo mejor DA de la hemicelulosa y calcio. El grupo T4 tuvo mejor DA de la fibra neutrodetergente y fue intermedio en DA de los minerales. Los resultados indicaron que los probióticos pueden ser una estrategia para la mejora del aprovechamiento de la dieta de potros, sobre todo cuando están compuestos por bacterias y levaduras vivas. La fitasa mejoró el aprovechamiento de la fibra cuando se administró en dosis de 205 FTU/kg de la dieta total, demostrando su potencial para la utilización en la nutrición equina.

\section{SUMMARY}

Additives have been used to improve quality diet and animal development. The objective was to assess the effects of probiotic or phytase supplementation on apparent digestibility of nutrients in 24 Mangalarga Marchador foals (16 
males, 8 females), aged $241.6 \pm 23.2$ days (mean \pm SD $/$ SEM), and weighing $216.7 \pm 27.8 \mathrm{~kg}$. The study lasted 28 days, the first 23 for diet and handling adaptation, and the last five days for fecal collection. The basal diet consisted of Cynodon pasture and pelleted concentrate (1.2 $\mathrm{kg} / 100 \mathrm{~kg}$ body weight), as well as water and mineral salt ad libitum. There were four treatments: basal diet (T1); basal diet $+5 \mathrm{~g} /$ day of $10^{9} \mathrm{CFU} / \mathrm{g}$ of $S$. cerevisiae (T2); basal diet $+2 \mathrm{~g} /$ day of $10^{8}$ $\mathrm{CFU} / \mathrm{g}$ of bacteria B. bifidum, E. faecium, $L$. acidophilus, L. plantarum and $10^{5} \mathrm{CFU} / \mathrm{g}$ of $S$. cerevisiae (T3); and basal diet + $1250 \mathrm{FTU} /$ day of phytase (T4). The DM intake was estimated with an external marker (LIPE ${ }^{\odot}$ ) associated with cecal in situ digestibility of DM. All foals were randomized by replicate using a $4 \times 2$ factorial, and results were compared using Student's t-test $(p<0.05)$. Group T3 showed better digestibility of crude protein, total minerals, calcium and phosphorus; whereas T2 had better digestibility of hemicellulose and calcium. Group T4 had better digestibility of neutral detergent fiber and intermediary values of minerals digestibility. Probiotics can be used as a nutritional strategy to improve the digestibility of a foal's diet, particularly when live bacteria and yeast culture are used. A phytase dose of 205 FTU/kg DM in the basal diet improved fiber digestibility, indicating its potential in equine nutrition.

\section{INTRODUCCIÓN}

La equinocultura es un importante sector de la agroganadería brasileña, siendo actualmente responsable de más de 3,2 millones de empleos directos o indirectos y representa casi 4 mil millones de dólares (US\$) al año en el ámbito del agronegocio nacional (Lima et al., 2006). Los potros, durante el primer año de vida, tienen un acelerado desarrollo corporal y por esta razón hay necesidad de una dieta que pueda atender sus requisitos nutricionales (NRC, 2007).

El uso de aditivos que pueden aportar beneficios nutricionales a los animales ha aumentado mucho en los últimos años, con el objetivo de mejorar la calidad de la dieta, estimular el desempeño animal y aumentar la ganancia económico-financiera de la ex- plotación ganadera. En la equinocultura, acompañando esa tendencia, se destacan los probióticos por la amplia utilización en las explotaciones, aunque sean pocos los trabajos publicados sobre el tema que comprueben sus efectos para la especie equina.

Los probióticos son microorganismos vivos añadidos a la dieta para mejorar el medio intestinal, especialmente el equilibrio de la microbiota (Fuller, 1989). La microbiota intestinal ejerce un papel de extrema importancia en la salud del hospedador al inducir cambios morfo-fisiológicos en el epitelio intestinal y el sistema inmunológico local. Participa, además, del sistema de defensa no inmunológico compitiendo con los microbios oportunistas por el aprovechamiento de los nutrientes y el espacio, y elaborando sustancias antimicrobianas, enzimas y vitaminas (Vanbelle et al., 1990; Losada y Olleros, 2002).

Moore et al. (1994) observaron una mayor concentración de protozoarios y bacterias celulolíticas en el ciego de los animales cuando añadieron levaduras a la dieta de los equinos, observando aumento de la digestibilidad de la materia seca (MS), proteína bruta (PB), fibra neutrodetergente (FDN) y fibra ácidodetergente (FDA). Hill y Gutsell (1998) observaron un aumento de la digestibilidad de la FDN y la absorción intestinal del fósforo $(\mathrm{P})$ en equinos que recibieron raciones con probióticos. Sin embargo, Hall et al. (1990) no observaron efecto de la suplementación con levaduras a niveles crecientes sobre la digestibilidad de la MS, PB, FDN y de la energía. Por otro lado, Kim et al. (1991) verificaron una mayor digestibilidad de la MS, PB, FDN, FDA, hemicelulosas y $\mathrm{P}$ en animales que consumieron una dieta con levaduras vivas y concluyeron que el mayor aprovechamiento de la PB y del P fue debido al estímulo de la actividad microbiana que aumentó tanto el reciclaje del nitrógeno endógeno como la producción de fitasa en el intestino grueso.

La dieta suplida con enzimas, especialmente fitasas, es actualmente un tema muy 
investigado en dietas para aves y cerdos, a causa del efecto que los fitatos ejercen en la absorción de los minerales. El fitato (hexafosfato de inositol) ocurre naturalmente en los complejos orgánicos de las plantas y constituye aproximadamente dos tercios del P total (Conte et al., 2003). En los equinos ocurre producción de fitasa por las bacterias presentes en el ciego y colon (Pagan, 1990; Van Doorn et al., 2004) pero ello no evita totalmente el efecto negativo de los fitatos pues el principal sitio donde ocurre la absorción de $\mathrm{P}$ en dietas ricas en concentrados proteicos es el intestino delgado (Schryver et al., 1972).

Van Doorn et al. (2004) verificaron la mejora de la absorción del calcio dietético (Ca), pero no del $\mathrm{P}$, en equinos que consumieron raciones con fitasa. Patterson et al. (2002) y Hainzea et al. (2004) tampoco encontraron efecto en la suplementación con fitasa sobre la digestibilidad y excreción fecal del $\mathrm{P}$ en los equinos.

Este trabajo se planteó ante la escasez de trabajos de investigación sobre la enzima fitasa y los probióticos en la dieta de equinos y teniendo en consideración la importancia que dichos aditivos pueden proporcionar al aprovechamiento de los nutrientes y el desempeño zootécnico de los animales. Los objetivos fueron evaluar dietas para equinos suplidas con probióticos, compuestos solamente por levaduras vivas o asociadas con bacterias vivas, y la acción de la fitasa sobre la digestibilidad aparente de los nutrientes en dietas para potros de la raza Mangalarga Marchador.

\section{MATERIAL YMÉTODOS}

El experimento se realizó en el Haras Catuni, situado próximo al municipio de Montes Claros - Minas Gerais - Brasil, durante el período de 22 de julio a 19 de agosto de 2006. Fueron utilizados 24 potros de la raza Mangalarga Marchador (16 machos y ocho hembras), siendo todos hijos del mismo semental y con medias de edad de 241,6 $\pm 23,2$ días y medias de peso vivo (PV) de $216,7 \pm 27,8 \mathrm{~kg}$. Los animales quedaron alojados en un prado de ocho hectáreas, formado por gramíneas del género Cynodon, en sistema de pastoreo continuo y con acceso a bebederos, saladeros cubiertos para la sal mineralizada y unidades de servicio para el suministro del concentrado. Las unidades de servicio son instalaciones individuales con comederos, donde se puede suministrar una dieta individualizada a los animales del experimento, sin la necesidad de confinarlos (Carvalho y Haddad, 1987).

El experimento tuvo una duración de 28 días, siendo los 23 días iniciales destinados a la adaptación de los animales a la dieta y al ambiente del alojamiento, y los cinco días finales destinados a la recogida de muestras de heces para los análisis posteriores. Inicialmente los animales fueron vermifugados y sometidos a baños garrapaticidas. Los potros fueron pesados y evaluados cuanto al escore corporal (Carrol y Huntington, 1988) al principio y el final del experimento.

La dieta estaba compuesta por gramíneas, como alimento forrajero, y concentrado comercial $^{2}$, además de agua y la sal mineralizada ${ }^{3}$ ad libitum. La composición químico-bromatológica del forraje y el concentrado se puede ver en la tabla $\mathbf{I}$.

El concentrado fue suministrado a razón de 1,2 kg para cada $100 \mathrm{~kg}$ de PV (NRC, 1989), siendo calculada de acuerdo con el peso de los animales en el inicio del período experimental. El concentrado fue dividido en dos porciones diarias, suministradas a las 7:30 y a las 15:30 horas, en las unidades de servicio localizadas dentro del pastizal.

Los grupos experimentales estaban formados con base en el siguiente criterio: cada cuatro potros del mismo sexo y edad próxima fueron sorteados para uno de los siguientes tratamientos:

\footnotetext{
${ }^{2}$ Equisul lactação 16 Floc $®$ - TOTAL Alimentos S./A. Três Corações. Minas Gerais. Brasil. ${ }^{3}$ Hiposal 80® - TOTAL Alimentos S./A.
} 
MOURA ETAL.

Tabla I. Composición de los ingredientes de la dieta, con base en la matéria seca. (Ingredients composition of the diet, as-dry matter basis).

\begin{tabular}{lccccc}
\hline Alimento & $\begin{array}{c}\text { Matéria seca } \\
(\%)\end{array}$ & $\begin{array}{c}\text { Energía digestible } \\
(\text { Mcal/kg) }\end{array}$ & $\begin{array}{c}\text { Proteína bruta } \\
(\%)\end{array}$ & $\begin{array}{c}\text { Lisina } \\
(\%)\end{array}$ & $\begin{array}{c}\text { Oxalato } \\
(\%)\end{array}$ \\
\hline Concentrado $^{1}$ & 89,97 & 3,65 & 18,89 & $0,87^{3}$ & - \\
Forraje $^{2}$ & 60,27 & 1,15 & 3,67 & $0,38^{4}$ & 0,30 \\
& & & & & \\
Alimento & FDN (\%) & FDA (\%) & Lignina (\%) & Cálcio (\%) & Fósforo (\%) \\
Concentrado & & & & 1,19 & 0,80 \\
Forraje $^{2}$ & 31,90 & 11,27 & - & 0,63 & 0,27 \\
\hline
\end{tabular}

${ }^{1}$ Equisul Lactação 16 Floc $\circledast$ - TOTAL Alimentos S./A. ${ }^{2}$ Gramíneas del género Cynodon. ${ }^{3}$ Niveles de garantia del fabricante. ${ }^{4} \mathrm{NRC}(1989)$.

Relación PB/ED e Ca/P total del dieta: 45,4 g/Mcal y 1,8:1, respectivamente. Relación Ca/oxalato del forraje: $2,1: 1$

T1 - dieta basal (control);

$\mathrm{T} 2$ - dieta basal $+5 \mathrm{~g} /$ día de probiótico de levaduras vivas

$\mathrm{T} 3$ - dieta basal $+2 \mathrm{~g} /$ día de probiótico de bacterias y levaduras vivas ${ }^{5}$; e

T4 - dieta basal + $1250 \mathrm{FTU} /$ día de fitasa $^{6}$.

Juntamente con el concentrado ofrecido a los animales por la mañana, fueron suministrados $10 \mathrm{ml}$ de aceite de maíz directamente en la boca de cada animal, como vehículo utilizado para los aditivos a ser testados.

El indicador externo $\operatorname{LIPE}^{\circledR}$ (Lanzetta et $a l ., 2009)$ fue suministrado por vía oral a la dosis diaria de $250 \mathrm{mg} / \mathrm{kg}$ siempre a las 15:30

\footnotetext{
${ }^{4}$ Biosaf®-LESSAFRE, Marcq-en-Baroeu, NordPas-de-Calais. France: mínimo por g: 1 x $10^{9}$ UFC de Saccharomyces cerevisiae.

${ }^{5}$ Florafort ${ }^{\circledR}$-Laboratório VITAFORT Ind. E Com. de Prod. Veterinários Ltda. Ribeirão Preto. São Paulo. Brasil: mínimo por g: 3,33 x $10^{7}$ UFC de Bifidobacterium bifidum, 1,66 x $10^{7}$ UFC de Enterococcus faecium, 3,33 x $10^{7}$ UFC de Lactobacillus acidophilus, 1,66 x 107 UFC de L. plantarum, e 3,33 x $10^{5}$ UFC de Saccharomyces cerevisiae.

${ }^{6}$ Natuphos 5000G®-BASF, Aktiengesell-schaft. Germany: mínimo por g: 5000 FTU.
}

horas durante los cinco días de la recogida de heces. Para la adecuada adaptación de los animales y la eliminación uniforme del indicador en las heces, la administración del indicador se inició 24 horas antes de empezar la recolección de las muestras de heces. Las muestras de heces fueron recogidas directamente de la ampolla rectal, siempre a la misma hora de la administración del indicador. Las muestras fueron acondicionadas en bolsas plásticas, identificadas por animal y día, y congeladas hasta el momento del análisis. Se recogieron así mismo muestras representativas de los alimentos suministrados a los animales para la evaluación de la composición químico-bromatológica de la dieta. Las muestras de forraje se recogieron por pastoreo simulado (Gardner, 1986).

Los análisis de la dieta y de las muestras de heces fueron realizados en el Laboratorio de Nutrición Animal de la Escuela de Veterinaria. Universidad Federal Minas Gerais (UFMG), según la técnica descrita por AOAC (1995), para: MS, PB, EB, Ca, P y oxalato; y la técnica de Van Soest et al. (1991), para FDN, FDA y lignina. El indicador externo LIPE $^{\circledR}$ fue analizado por espectroscopía en infrarrojo (Lanzetta et al., 2009), en el De- 
partamento de Química del Instituto de Ciências Exactas. UFMG.

La técnica de digestibilidad in situ de los alimentos, adaptada de Huntington y Givens (1995), fue realizada durante los días 24 a 28 de agosto de 2006, utilizándose un equino ciego-fistulado (Lowe et al., 1970) del Laboratorio de Investigaciones en Salud Equina de la Universidad Federal Rural de Rio de Janeiro. Se utilizaron bolsas de nylon de porosidad de $45 \mu$ (Tenyl $\left.{ }^{\circledR}\right)$, con área interna de 6,5 x 20,0 cm, según Hyslop et al. (1999), y una relación de capacidad por área de $20 \mathrm{~g} / \mathrm{cm}^{2}$. En cada bolsa se introdujeron $5,2 \mathrm{~g}$ de muestras de forraje presecado y pienso molidas a $2 \mathrm{~mm}$. A continuación fueron incubadas durante 48 horas y luego lavadas manualmente con agua a temperatura ambiente y puestas a secar en la estufa con ventilación forzada a $55^{\circ} \mathrm{C}$, durante más de 48 horas. Se realizaron dos incubaciones para cada alimento. Al término de este ensayo, los residuos de las bolsas correspondientes al mismo alimento fueron mezclados, homogeneizados y molidos a $1 \mathrm{~mm}$ para el análisis posterior del contenido de MS (AOAC, 1995) en el Laboratorio de Nutrición Animal de la Escuela de Veterinaria. UFMG.

La producción fecal (PF) fue calculada utilizando el indicador externo LIPE $^{\circledR}$, de acuerdo con la siguiente fórmula (Lanzetta et al., 2009):

$$
\text { PF }(k g)=\underline{\text { LIPE }^{\circledR}} \frac{\text { suministrado }(\mathrm{g}) \times 100}{(\mathrm{Ai} / \mathrm{MS} \text { total })}
$$

donde:

MS total= materia seca fecal total e

$\mathrm{A}=$ relación logarítmica de las intensidades de absorción de las bandas de longitud de onda a $1050 \mathrm{~cm}^{-1} / 1650 \mathrm{~cm}^{-1}$. El Ai fue calculado mediante la siguiente fórmula: $A \mathrm{i}=\mathrm{A} .1050$ / A. 1650 , siendo que $A=\log I_{0} / I$ (donde $I_{0}>$ intensidad e $\mathrm{K}<$ intensidad).

Las pérdidas de MS después de las incubaciones cecales in situ fueron expresadas como coeficientes de digestibilidad in situ de la MS (DISMS), determinados por el residuo de cada saco, de los alimentos voluminosos y pienso, de acuerdo con la fórmula:

$$
\operatorname{DISMS}(\%)=1-\frac{\text { residuo de la bolsa }(\mathrm{g})}{(\mathrm{I} \times \mathrm{MS} \text { alimento })}
$$

donde:

$\mathrm{I}=$ a cantidad de alimento $(\mathrm{g})$ metido en cada bolsa; MS Alimento = el nivel de MS determinada a 105ㄷ del alimento (AOAC, 1995).

Tras la obtención de los valores de producción fecal (PF) y de digestibilidad in situ de la MS (DISMS) de los alimentos de la dieta, se realizaron los cálculos para la estimación del consumo de MS de la dieta total y del alimento voluminoso por los animales, de acuerdo con la fórmula (Moura et al., 2009):

Consumo $(\mathrm{kg} \mathrm{MS})=$ producción de heces $\times 100$ (100 - digestibilidad)

Como el consumo diario del pienso era conocido y su DISMS fue determinada, se calculó la cantidad de heces producidas correspondiente a la porción no aprovechada de ese alimento. Entonces el consumo diario de forraje ( $\mathrm{kg}$ MS/día) fue estimado utilizando la DISMS del forraje y la PF correspondiente de ese alimento (resultado de la diferencia entre la PF total estimada por el indicador externo LIPE $^{\circledR}$ y PF del pienso). El consumo diario total de MS resultó de la suma de los consumos de pienso y forraje.

A partir de los resultados de los análisis del laboratorio, de las estimaciones del consumo de alimentos y la producción fecal se calcularon los coeficientes de digestibilidad aparente de la materia seca(DAMS), proteína bruta (DAPB), energía bruta (DAEB), fibra neutrodetergente (DAFDN), hemi-celulosas (DAHCEL), fibra ácidodetergente (DAFDA), materia mineral(DAMM), calcio (DACa) y fósforo (DAP), a través de la fórmula descrita por Pond et al. (1995): 
$\mathrm{DA}(\%)=($ Nut. cons. $(\mathrm{g})-$ Nut. heces $(\mathrm{g})) \times 100$ Nutriente consumido $(\mathrm{g})$

donde:

$\mathrm{DA}=$ coeficiente de digestibilidad aparente;

Nut. cons. = nutriente consumido; $y$

Nut. heces $=$ nutriente en las heces.

El diseño estadístico fue íntegramente al azar, en esquema factorial $4 \times 2$ (cuatro tratamientos y dos sexos), con seis repeticiones por tratamiento (cuatro machos y dos hembras), totalizando 24 observaciones. Las medias de los coeficientes de digestibilidad aparente se sometió al análisis de varianza y comparadas por el test de t de Student $(\mathrm{p}<0,05)$.

\section{RESULTADOSYDISCUSIÓN}

La estimativa de la producción total de heces por los potros fue de 2,68 $\pm 0,41 \mathrm{~kg}$ MS/animal/día y la digestibilidad in situ de la MS del pienso concentrado y forrajero fue de $84,16 \%$ y $33,36 \%$, respectivamente. El experimento fue desarrollado en la estación seca y por lo tanto, la baja digestibilidad in situ del forraje se debe a la mayor concentración de la lignina presente en los pastos en el periodo seco (Moura et al., 2009). El consumo de MS total por los potros varió de 5,49 a 6,16 kg MS/día (2,4 a 2,8\% del peso vivo/animal) y está dentro de lo indicado por NRC (2007).

En la tabla II se pueden observar los coeficientes de digestibilidad aparente de la MS, PB, EB, FDN, HCEL y FDA de la dieta suministrada a los animales del experimento.

En el grupo T2 hubo un aumento de $8,86 \%$ en la digestibilidad aparente de la HCEL. El efecto positivo posiblemente ocu-

Tabla II. Medias de los coeficientes de digestibilidad aparente (DA) de MS, PB, EB, FDN, HCEL y FDA de los grupos experimentales. (Mean apparent digestibility coefficients of dry matter, crude protein, gross energy, FDN, hemicellulose and FDA of the experimental groups).

\begin{tabular}{lccccccccc}
\hline Grupos & $\begin{array}{c}\text { macho } \\
(\%)\end{array}$ & $\begin{array}{c}\text { DAMS } \\
\text { hembra } \\
(\%)\end{array}$ & $\begin{array}{c}\text { media } \\
(\%)\end{array}$ & $\begin{array}{c}\text { macho } \\
(\%)\end{array}$ & $\begin{array}{c}\text { DAPB } \\
\text { hembra } \\
(\%)\end{array}$ & $\begin{array}{c}\text { media } \\
(\%)\end{array}$ & $\begin{array}{c}\text { macho } \\
(\%)\end{array}$ & $\begin{array}{c}\text { DAEB } \\
\text { hembra } \\
(\%)\end{array}$ & $\begin{array}{c}\text { media } \\
(\%)\end{array}$ \\
T1 & 54,86 & 52,57 & $54,10^{\mathrm{AB}}$ & 70,45 & 63,81 & $68,24^{\mathrm{B}}$ & 51,73 & 50,66 & $51,37^{\mathrm{AB}}$ \\
T2 & 54,17 & 51,35 & $53,23^{\mathrm{B}}$ & 69,63 & 67,15 & $68,80^{\mathrm{B}}$ & 51,17 & 47,68 & $50,01^{\mathrm{B}}$ \\
T3 & 55,60 & 55,70 & $55,63^{\mathrm{A}}$ & 73,19 & 71,94 & $72,77^{\mathrm{A}}$ & 53,45 & 53,62 & $53,51^{\mathrm{A}}$ \\
T4 & 53,54 & 51,12 & $52,73^{\mathrm{B}}$ & 68,69 & 65,56 & $67,65^{\mathrm{B}}$ & 50,08 & 49,42 & $49,86^{\mathrm{B}}$ \\
Media & $54,54^{\mathrm{a}}$ & $52,68^{\mathrm{a}}$ & 53,92 & $70,49^{\mathrm{a}}$ & $67,12^{\mathrm{a}}$ & 69,37 & $51,61^{\mathrm{a}}$ & $50,35^{\mathrm{a}}$ & 51,19 \\
& & & & & & & & & \\
Grupos & macho & DAFDN & & & DAHCEL & & & DAFDA & \\
& $(\%)$ & $(\%)$ & $(\%)$ & $(\%)$ & $(\%)$ & $(\%)$ & $(\%)$ & $(\%)$ & $(\%)$ \\
T1 & 42,73 & 40,38 & $41,95^{\mathrm{B}}$ & 43,92 & 44,61 & $44,15^{\mathrm{B}}$ & 41,60 & 36,43 & $39,88^{\mathrm{A}}$ \\
T2 & 42,80 & 41,61 & $42,40^{\mathrm{AB}}$ & 49,02 & 46,14 & $48,06^{\mathrm{A}}$ & 36,80 & 37,44 & $37,01^{\mathrm{B}}$ \\
T3 & 42,95 & 43,42 & $43,11^{\mathrm{AB}}$ & 46,71 & 46,93 & $46,78^{\mathrm{AB}}$ & 39,30 & 40,03 & $39,54^{\mathrm{AB}}$ \\
T4 & 44,02 & 42,07 & $43,37^{\mathrm{A}}$ & 46,95 & 45,53 & $46,47^{\mathrm{AB}}$ & 41,19 & 38,88 & $40,42^{\mathrm{A}}$ \\
Média & $43,13^{\mathrm{a}}$ & $41,87^{\mathrm{a}}$ & 42,71 & $46,65^{\mathrm{a}}$ & $45,80^{\mathrm{a}}$ & 46,37 & $39,72^{\mathrm{a}}$ & $38,19^{\mathrm{a}}$ & 39,21 \\
\hline
\end{tabular}

T1: control; T2: probiótico levaduras vivas; T3: probióticos bacterias y levaduras vivas; T4: fitasa. $\mathrm{CV}=5,05 \%$ (DAMS); 5,71\% (DAPB); 5,90\% (DAEB); 3,75\% (DAFDN); 7,07\% (DAHCEL); 8,29\% (DAFDA).

ABabLetras distintas, mayúsculas en la columna e minúsculas en la línea, indican medias diferentes por la prueba t de Student $(p<0,05)$. 
rrió debido a la reducción del potencial redox en el ambiente intestinal, como sugirieron Newbold et al. (1996) cuando estudiaron la acción de la levadura $S$. cerevisiae en los rumiantes. Dichos investigadores concluyeron que estos microorganismos disminuyen la concentración de oxígeno libre en el rumen contribuyendo al mantenimiento de la anaerobiosis lo cual es particularmente favorable para la bacterias celulolíticas. El resultado favorable del grupo T2 resultó de acuerdo con Kim et al. (1991) y Moore et al. (1994) que también observaron mayor digestibilidad aparente de la fibra en equinos que consumieron raciones suplidas con levaduras, sugiriendo que este aditivo mejora la digestión de la dieta al favorecer a la microbiota presente en el tracto digestivo equino.

La enzima fitasa (grupo T4) mejoró el aprovechamiento de la FDN en comparación con el grupo control. Por otro lado, los animales que consumieron probióticos presentaron resultados intermedios. La hipótesis que mejor explica el efecto positivo de la fitasa sobre el aprovechamiento de la fibra fue planteada por Younes et al. (1996). Estos autores sugirieron que los minerales, como calcio y fósforo, pueden ayudar en el mantenimiento de la microbiota celulolítica al neutralizar los ácidos orgánicos derivados del metabolismo bacteriano a través de la formación de sales (acetato, butirato y lactato), evitando de esta manera la disminución acentuada del pH. La acción de esta enzima sobre los minerales puede haber contribuido al control del $\mathrm{pH}$ intestinal, ayudando a la estabilidad de la población microbiana, particularmente celulolítica, lo que provocaría, como consecuencia, el mejor aprovechamiento de la fibra.

También se puede observar en la tabla II, con respecto a FDA, que el grupo T2 resultó inferior a los grupos T4 e T1. El grupo T3 presentó, a su vez, valores intermedios. La FDA es la porción menos digestible de la pared celular, compuesta por celulosa y lignina. La lignina es indigestible e interfie- re en la digestión de la celulosa por actuar como barrera física que impide el ataque microbiano. El forraje utilizado se encontraba en avanzado estado de madurez, con $3,67 \%$ de PB y $9,99 \%$ de lignina. Por ello, era esperado que los valores entre los grupos fuesen parecidos, pues aunque los probióticos mejorasen la microbiota intestinal, las bacterias no podrían colonizar y digerir la celulosa protegida por la lignina. Luego, las diferencias observadas con relación a la DAFDA, con menores valores en los grupos suplementados con probióticos (T2 e T3), probablemente ocurrieran en razón de la metodología analítica empleada (Van Soest et al., 1991).

El coeficiente de digestibilidad aparente de la PB (DAPB) fue superior en el grupo T3 $(\mathrm{p}<0,05)$, demostrando la acción benéfica del probiótico compuesto de bacterias y levaduras vivas sobre la actividad proteolítica de la microbiota intestinal. La mejora de la DAPB podría deberse a la disminución de la excreción del nitrógeno fecal, a razón de un estímulo en el reciclaje del nitrógeno endógeno, como confirmaron Glade y Sist (1988), y propusieron Kim et al. (1991). Además, una hipótesis sería la mayor actividad proteolítica de la microbiota intestinal, a partir de la porción anterior del tracto digestivo de los equinos. De acuerdo con Yuki et al. (2000) las bacterias del genero Lactobacillus son las más importantes que se encuentran en el trato digestivo de los equinos. La presencia de estas bacterias explicaría el efecto benéfico solamente del grupo T3. Sin embargo, para mejor elucidación de esa hipótesis se necesitan estudios de digestión parcial en el aparato digestivo de los equinos. La ingestión de proteína digestible (PD) resultó parecida entre los grupos, siendo $415,3 \mathrm{~g}$ para el grupo T3, 395,0 g para el grupo T4, 384,0 g para el grupo T1 y $383,1 \mathrm{~g}$ para el grupo T2, ya que el consumo de voluminoso fue voluntario.

El grupo que recibió suplementación solamente con levaduras vivas (T2) no resultó diferente del grupo control con rela- 
ción a la DAPB, siendo inferior en la DAEB cuando se comparó con el grupo T3. Eso sugiere que las bacterias ácido-lácticas asociadas con Saccharomyces cerevisiae del probiótico suministrado al grupo T3 pueden haber sufrido una acción potenciadora para el aprovechamiento de la dieta por los animales, acción conocida como sinergismo entre microorganismos. Sin embargo, para confirmar esta hipótesis habría que ampliar las evaluaciones microbiológicas entre las especies presentes en este aditivo, como el recuento diferencial de los microorganismos y la presencia de posibles antagonismos entre especies.

Otra hipótesis que podría justificar el importante efecto del probiótico sería la utilización de microorganismos que habitan naturalmente el tracto digestivo de la especie utilizada en el experimento, facilitando la acción contra los microorganismos oportunistas. Entre las especies que componían el probiótico suministrado a los animales del grupo T3, estaban presentes dos bacterias del género Lactobacillus (L. acidophilus y L. plantarum). Según Yuki et al. (2000), este género es predominante en la microbiota normal de los equinos. A su vez, Yuyama et al. (2000) encontraron un aumento de $6 \%$ en la ganancia de peso en potros neonatos suplementados con probióticos compuesto por cinco cepas de Lactobacillus ( 1 - 4 x $10^{10}$ $\mathrm{UFC} / \mathrm{g}$ ) aislados del ciego de equinos, con que afirmaron que la utilización de microorganismos específicos para la microbiota equina es un requisito importante para obtener resultados favorables con la utilización de los probióticos. Luego, la elección de cepas probióticas especie-específicas para equinos, puede ser un punto clave e importante para la selección de suplementos probióticos capaces de promover las ventajas nutricionales deseadas.

En la tabla III se pueden ver las medias de digestibilidad aparente de la materia mineral (DAMM), del calcio (DACa) y del fósforo (DAP).

Los animales del grupo T3 presentaron DAMM 16,09\% superior al control $(p<0,05)$, y los grupos T4 y T2 presentaron valores intermediarios. Los grupos que consumieron probióticos presentaron un aumento de $17,06 \%$ en la DACa, comparado al grupo control. Según Ybarra et al. (2003), uno de los posibles mecanismos involucrados en el aumento de la biodisponibilidad de minerales a través de la suplementación con probióticos es la disminución del $\mathrm{pH}$ del

Tabla III. Medias de los coeficientes de digestibilidad aparente (DA) de la MM, Ca y P de los grupos experimentales. (Mean apparent digestibility coefficients of total minerals, calcium and phosphorus of the experimental groups).

\begin{tabular}{lccccccccc}
\hline Grupos & $\begin{array}{c}\text { DAMM } \\
\text { macho } \\
(\%)\end{array}$ & $\begin{array}{c}\text { hembra } \\
(\%)\end{array}$ & $\begin{array}{c}\text { media } \\
(\%)\end{array}$ & $\begin{array}{c}\text { macho } \\
(\%)\end{array}$ & $\begin{array}{c}\text { DACa } \\
\text { hembra } \\
(\%)\end{array}$ & $\begin{array}{c}\text { media } \\
(\%)\end{array}$ & $\begin{array}{c}\text { macho } \\
(\%)\end{array}$ & $\begin{array}{c}\text { DAP } \\
\text { hembra } \\
(\%)\end{array}$ & $\begin{array}{c}\text { media } \\
(\%)\end{array}$ \\
T1 & 36,85 & 27,75 & $33,81^{\mathrm{B}}$ & 47,45 & 31,64 & $42,18^{\mathrm{B}}$ & 34,57 & 23,49 & $30,88^{\mathrm{B}}$ \\
T2 & 39,21 & 31,43 & $36,61^{\mathrm{AB}}$ & 50,26 & 47,22 & $49,25^{\mathrm{A}}$ & 37,11 & 28,12 & $34,11^{\mathrm{B}}$ \\
T3 & 40,40 & 36,96 & $39,25^{\mathrm{A}}$ & 49,73 & 49,04 & $49,50^{\mathrm{A}}$ & 42,40 & 40,27 & $41,69^{\mathrm{A}}$ \\
T4 & 39,13 & 32,09 & $36,78^{\mathrm{AB}}$ & 49,52 & 41,73 & $46,93^{\mathrm{AB}}$ & 35,55 & 31,96 & $34,35^{\mathrm{AB}}$ \\
Media & $38,90^{\mathrm{a}}$ & $32,06^{\mathrm{b}}$ & 36,62 & $49,24^{\mathrm{a}}$ & $42,41^{\mathrm{b}}$ & 46,96 & 37,41 & $30,96^{\mathrm{a}}$ & 35,26 \\
\hline
\end{tabular}

T1: control; T2: probiótico levaduras vivas; T3: probióticos bacterias y levaduras vivas; T4: fitasa. $C V=14,98 \%$ (DAMM); $14,52 \%$ (DACa); $24,3 \%$ (DAP).

Letras distintas, mayúsculas en la columna y minúsculas en la línea, indican medias diferentes por el test $t$ de Student $(p<0,05)$. 
contenido intestinal, resultante de la producción de ácidos grasos de cadena corta, lo que llevaría a la solubilización de parte de los minerales presentes o de complejos previamente formados, aumentando de esta manera la concentración de las fracciones solubles y absorción vía paracelular.

El grupo T3 resultó superior a los grupos $\mathrm{T} 2 \mathrm{y}$ control, de 22 a $35 \%$ en la DAP, mientras que el grupo T4 presentó valores intermedios. Este resultado esta de acuerdo con la hipótesis de Pagan (1990) quien sugiere que la fitasa producida por las bacterias celulolíticas proporcionan mayor disponibilidad de P para los equinos. La mejor disponibilidad del $\mathrm{P}$ en el grupo T3 indicaría una vez más que los microorganismos presentes en el probiótico pueden haber potenciado la acción de la microbiota digestiva.

Según Schryver et al. (1972), el sitio de absorción de P en la especie equina varia de acuerdo con la composición de la dieta, siendo mayor en el intestino delgado, cuando grandes cantidades de concentrados son incluidos en la dieta. Se esperaba, por lo tanto, que al suministrar fitasa exógena a los animales, la disponibilidad de fósforo fítico antes de su sitio de absorción aumentaría su aprovechamiento por el animal. Sin embargo, los potros que consumieron fitasa presentaron la digestibilidad de los minerales semejante al de grupo control. La dosis media utilizada fue de $544 \mathrm{FTU} / \mathrm{kg}$ MS del concentrado, según las recomendaciones del fabricante, lo que ha correspondido tras el cálculo del consumo de MS total, a una dosis de $205 \mathrm{FTU} / \mathrm{kg}$ de MS de la dieta total. Las hipótesis que justifican dichos resultados son que la dosificación utilizada puede haber sido insuficiente o que puede haber ocurrido la desactivación de la enzima a lo largo del tracto digestivo de los potros.

Los resultados están de acuerdo con los de Morris-Stoker et al. (2001), citado por Patterson et al. (2002), y de Van Doorn et al. (2004) que en trabajos semejantes tampoco encontraron efecto sobre la disponibilidad de $\mathrm{P}$ en equinos suplementados con la enzima fitasa. Así mismo Patterson et al. (2002) no han encontrado diferencias en la excreción fecal y urinaria de $\mathrm{P}$ en equinos suplementados con fitasa, a dosis de $0,300,600$ y $900 \mathrm{FTU} / \mathrm{kg}$ de dieta.

\section{CONCLUSIONES}

De acuerdo con las condiciones de desarrollo del presente trabajo y teniendo en cuenta los resultados obtenidos, se puede concluir que:

Los aditivos probióticos pueden ser utilizados como estrategia nutricional para la mejora del aprovechamiento de la dieta por potros destetados, principalmente cuando están compuestos por bacterias y levaduras vivas.

La suplementación de la dieta con fitasa exógena a una dosis de $205 \mathrm{FTU} / \mathrm{kg}$ MS en la dieta total (544 FTU/kg MS de concentrado) presentó efecto benéfico en el aprovechamiento de la fibra para potros destetados, demostrando su potencial para la utilización en la nutrición equina.

Más estudios son necesarios sobre la preparación y suministro de productos probióticos comerciales, evaluados tanto con relación a las especies a que van destinados, como con relación al potencial de la fitasa sobre el aprovechamiento de los nutrientes de la dieta, destacando las dosificaciones adecuadas y la estabilidad del producto en el tracto digestivo equino.

\section{BIBLIOGRAFÍA}

AOAC. 1995. Association of Official Analytical Chemistry. Official methods of analysis. $16^{\text {th }}$ ed. AOAC International. Arlington. 1025 pp.

Carrol, C.L. and Huntington, P.J. 1988. Body

condition scoring and weight estimation of horses. Equine Vet. J., 20: 41-45.

Carvalho, R.T.L. e Haddad, C.M. 1987. A criação e a nutrição de cavalos. Editora Globo. Rio de 
Janeiro. $180 \mathrm{pp}$.

Conte, A.J., Teixeira, A.S., Fialho, E.T., Schoulten, N.A. e Bertechini, A.G. 2003. Efeito da fitase e xilanase sobre o desempenho e as características ósseas de frangos de corte alimentados com dietas contendo farelo de arroz. Braz. J. Anim. Sci., 32: 1147-1156.

Fuller, R. 1989. Probiotic in man and animals. A review. J. Appl. Bacteriol., 66: 365-378.

Gardner, A.L. 1986. Técnicas de pesquisa em pastagens e aplicabilidade de resultados em sistemas de produção. II CA/Embrapa. Brasília. $197 \mathrm{pp}$.

Glade, M.J. and Sist, M.D. 1988. Dietary yeast culture supplementation enhances urea recycling in the equine large intestine. Nutr. Reports Intern., 37: 11-17.

Hainzea, M.T.M., Muntifering, R.B., Wood, C.W., McCall, C.A. and Wood, B.H. 2004. Faecal phosphorus excretion from horses fed typical diets with and without added phytase. Anim. Feed Sci. Tech., 117: 265-279.

Hall, R.R., Jackson, S.G., Baker, J.P. and Lowry, S.R. 1990. Influence of yeast culture supplementation on ration digestion by horses. J. Equine Vet. Sci., 10: 130-134.

Hill, J. and Gutsell, S. 1998. Effect of supplementation of a hay and concentrate diet with live yeast culture on the digestibility of nutrients in 2 and 3 year old riding school horses. Proc. Brit. Soc. Anim. Sci., 7: 128.

Huntington, J.A. and Givens, D.L. 1995. The in situ technique for studying the rumen degradation of feeds: a review of the procedure. Nutr. Abst. Rev.(Series B), 65: 63-93.

Hyslop, J.J., Stefansdottir, G.J., Mclean, B.M.L., Longland, A.C. and Cuddeford, D. 1999. In situ incubation sequence and its effect on degradation of food components when measured in the caecum of ponies. An. Sci., 69: 147-155.

Kim, S.M., Kim, C.M., Lee, H.K., Park, W.P., Lim, Y.J., Lim, B.I. and Chung, T.Y. 1991. Evaluation of nutrient values of some feedstuffs, and the effects of yeast culture supplementation on digestibilities of nutrients and blood parameter in horse. Korean J. Anim. Nutr. Feed., 15: 272280.

Lanzetta, V.A.S., Rezende, A.S.C., Saliba, E.O.S., Lana, A.M.Q., Rodriguez, N.M. e Moss, P.C.B.
2009. Validação do Lipe $^{\circledR}$ como método para determinar a digestibilidade dos nutrientes pelos eqüinos. Braz. J. Anim. Sci., 38: 69-74.

Lima, R.A.S., Shirota, R. e Barros, G.S.C. 2006. Estudo do complexo do agronegócio cavalo. Relatório Final. CEPEA/ESALQ/USP. Piracicaba. $251 \mathrm{pp}$.

Losada, M.A. and Olleros, T. 2002. Towards a healthier diet for the colon: the influence of fructooligosaccharides and lactobacilli on intestinal health. Nutr. Res., 22: 71-84.

Lowe, J.E., Hintz, H.F. and Schryver, H.F.A. 1970. A new technique for long-term cecal fistulation in ponies. Am. J. Vet. Res., 31: 1109-1111.

Moore, B.E., Newman, K.E. and Spring, P. 1994. Effect of yeast culture (Yea-Sacc1026) on microbial populations and digestion in the cecum and colon of the equine. J. Anim. Sci., 72: 252253.

Moura, R.S., Saliba, E.O.S., Almeida, F.Q., Lana, A.M.Q., Silva, V.P. and Rezende, A.S.C. 2009. Feed efficiency in Mangalarga Marchador foals fed diet supplemented with probiotics or phytase. Braz. J. Anim. Sci., 38: 1045-1050.

Newbold, C.J., Wallace, R.J. and Mcintosh, F.M. 1996. Mode of action of the yeast Saccharomyces cerevisiae as a feed additive for ruminants. Brit. J. Nutr., 76: 249-261.

NRC. 1989. National Research Council. Nutrient requeriments of horses. $5^{\text {th }}$ ed. National Academy of Science. Washington. $100 \mathrm{pp}$.

NRC. 2007. National Research Council. Nutrient requeriments of horses. $6^{\text {th }}$ ed. National Academy of Science. Washington. $341 \mathrm{pp}$.

Pagan, J.D. 1990. Effect of yeast culture supplementation on nutrient digestibility in mature horses. J. Anim. Sci., 68: 371.

Patterson, D.P., Cooper, S.R., Freeman, D.W. and Teeter, R.G. 2002. Effects of varying levels of phytase supplementation on dry matter and phosphorus digestibility in horses fed a common textured ration. J. Equine Vet. Sci., 22: 456-459.

Pond, W.G., Church, D.C and Pond, K.R. 1995. Basic animal nutrition and feeding. $4^{\mathrm{a}} \mathrm{ed}$. John Wiley \& Sons. New York. 615 pp.

Schryver, H.F., Hintz, H.F., Craig, P.H., Hogue, D.E. and Lowe, J.E. 1972. Site of phosphorus absorption from the intestine of the horse. $J$. Nutr., 102: 143-148.

Van Soest, P.J., Robertson, J.B. and Lewis, B.A. 


\section{PROBIÓTICOS Y FITASA EN DIETAS PARA POTROS MANGALARGA MARCHADOR}

1991. Methods for dietary fiber, neutral detergent fiber and nonstarch polysaccharides in relation to animal nutrition. J. Dairy Sci., 74: 3583-3597.

Van Doorn, D.A., Everts, H., Wouterse, H. and Beynen, A.C. 2004. The apparent digestibility of phytase phosphorus and the influence of supplemental phytase in horses. J. Anim. Sci., 82: 1756-1763.

Vanbelle, M., Teller, E. and Focant, M. 1990. Probiotics in animal nutrition: a review. Arch. Anim. Nutr., 40: 543-567.

Ybarra, L.M., Costa, N.M.B., Gibson, G.R. e Ferreira, C.L.L.F. 2003. Influência de probióticos e prebióticos na absorção de minerais. Em: Ferreira, C.L.L.F. (Ed.). Prebióticos e probióticos. Atualizações e prospecção. UFV. Viçosa. pp.
79-101.

Younes, H., Demigné, C. and Rémés, Y.C. 1996. Acidic fermentation in the caecum increases absorption of calcium and magnesium int he large intestine of the rat. Brit. J. Nutr., 75: 301 314.

Yuki, N., Shimazaki, T., Kushiro, A., Watanabe,K., Uchida, K., Yuyama, T. and Morotomi, M. 2000. Colonization of the stratified squamous epithelium of the non-secreting area of horse stomach by lactobacilli. Appl. Environ. Microb., 66: 50305034.

Yuyama, T., Yusa, S., Takai, S., Tsubaki, S., Kado, Y. and Morotomi, M. 2000. Evaluation of a hostspecific Lactobacillus probiotic in neonatal foals. Inter. J. Appl. Res. Vet. Med., 2: 26-33. 